\title{
Foraging mode shift in varying environmental conditions by dunlin Calidris alpina
}

\author{
Tomohiro Kuwae ${ }^{1, *}$, Eiichi Miyoshii ${ }^{1}$, Shinji Sassa ${ }^{2}$, Yoichi Watabe ${ }^{2}$ \\ ${ }^{1}$ Coastal and Estuarine Environment Research Group, and ${ }^{2}$ Soil Mechanics and Geo-Environment Research Group, \\ Port and Airport Research Institute, 3-1-1, Nagase,Yokosuka 239-0826, Japan
}

\begin{abstract}
Predators may have a series of alternative foraging modes. Under the food resource maximization hypothesis, predators are expected to shift between foraging modes such that they attain the highest intake rate in response to prey availability and constraints varying with environmental conditions. To test this hypothesis, we measured foraging action rate (actions per unit time), capture rate (captures per unit time), and intake rate (amount of energy and nutrients per unit time) for 2 foraging modes, pecking (feeding on epifauna at the sediment surface) and probing (feeding on infauna by inserting the bill into the sediment), in dunlin Calidris alpina on an intertidal sandflat. The birds chose their foraging mode to attain higher feeding success, i.e. individuals that obtained higher capture and intake rates by pecking allocated a higher proportion of foraging effort to pecking, and vice versa. The birds shifted foraging mode from probing to pecking with increased time after emersion. The shift may be related to decreasing efficiency of probing due to increases in the costs of energy and time caused by decreasing sediment penetrability (increasing hardness) with time after emersion. Our in situ study empirically suggests that, while environmental constraints reduce the predators' foraging mode flexibility, the birds show individual-based appropriate adjustments in their foraging mode to attain a higher intake rate at a given time and patch. This extends the ideal forager model for patch choice into foraging mode choice.
\end{abstract}

KEY WORDS: Decision making · Feeding ecology · Foraging behavior · Intertidal ecosystems Shorebirds

\section{INTRODUCTION}

Optimal foraging theory predicts that foraging decisions are based on a maximization of currencies (Stephens \& Krebs 1986, Ydenberg \& Hurd 1998, Bautista et al. 2001). Given that animals are expected to maximize food intake while foraging (Bautista et al. 2001), predators that have foraging mode alternatives should decide how to eat, i.e. they should choose the mode that attains a higher intake rate than others, in addition to where and what to eat. Moreover, multimodal foraging generalists should shift their foraging mode in response to changes in prey availability and foraging constraints that vary with environmental conditions.
A prey density-dependent mode shift has been theoretically demonstrated (Norberg 1977). Empirically, foraging mode shifts have been studied in relation to varying prey availability induced, variously, by prey size (Helfman \& Winkelman 1991), seasonality (Baker \& Baker 1973, Zwarts \& Esselink 1989, Lister \& Aguayo 1992), temperature (Nebel \& Thompson 2005), microhabitats (Fausch et al. 1997), and tidal cycles (Zwarts \& Esselink 1989). Also, environmental (abiotic) conditions other than prey availability may induce foraging mode shifts. For example, light levels can trigger mode shifts in prey detection mechanisms, such that visual foraging is employed during the day and tactile foraging at night (McNeil et al. 1992, Rojas et al. 1999). However, while foragers are hypothesized to consis- 
tently assess and adjust their foraging behavior with ideal knowledge (van Gils et al. 2006) and, as a consequence, attain higher intake rates, to our knowledge, there is no in situ study providing quantitative evidence in terms of shifts in foraging mode.

Small shorebirds, such as the family Scolopacidae, undertake both visual and tactile foraging using 2 main foraging modes, pecking and probing (Burton 1974), although several specialized birds have more modes, e.g. surface tension transport and biofilm grazing (Elner et al. 2005, Estrella et al. 2007, Kuwae et al. 2008). Pecking is characterized by feeding on epifaunal prey at the sediment surface, and probing consists of inserting the bill into the sediment, allowing capture of infaunal prey. Prey items may be hidden and/or vertically mobile, often causing capture failure (Kuwae 2007). Shorebirds make their foraging decisions based on a trade-off between rewards and costs (Gerritsen \& van Heezik 1984, Mouritsen \& Jensen 1992, Le V. dit Durell 2000). Probing may appear more rewarding in terms of success rate on profitable prey than pecking because of the higher prey availability potential within the extended search depths (Myers et al. 1980, Mouritsen \& Jensen 1992). However, probing can cost more than pecking in terms of time and energy (Gerritsen \& van Heezik 1984) or potential risk of bill wear due to friction with sediment particles (Le V. dit Durell 2000).

Sediment penetrability is a major environmental constraint for probing shorebirds, resulting in preference of higher penetrability microhabitats (Gerritsen \& van Heezik 1984, Grant 1984, Mouritsen \& Jensen 1992). Penetrability affects the cost of bill insertion as well as the ability to detect and capture prey, because lower penetrability limits bill movement for prey search and capture below the sediment surface (Myers et al. 1980). Intertidal sediment penetrability, in turn, decreases with the time after emersion (exposure to air) due to the development of suction, i.e. negative porewater pressure relative to atmospheric air pressure (Hryciw \& Dowding 1987, Sassa \& Watabe 2007). Therefore, for permeable sediments, relative profitability between pecking and probing may be hypothesized to be dependent on the tidal cycle.

Here we examine foraging mode decision in overwintering dunlin Calidris alpina (L.) (Fig. 1) on a sandflat in Tokyo Bay, Japan. Dunlin are ideal organisms for testing mode choice and shifts, because, compared to other shorebird species, they show greater flexibility in foraging modes in response to environmental changes (Baker \& Baker 1973). Using a digital camcorder with a telescopic lens, we measured foraging action rate, capture rate, and intake rate of dunlin throughout tidal emersion periods to test 2 hypotheses: (1) individuals that attain higher capture and/or intake rates by one of 2 modes allocate proportionately

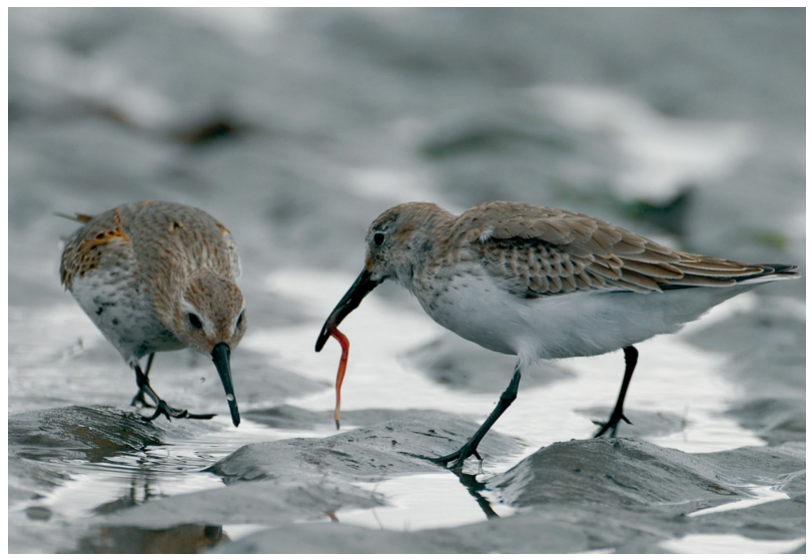

Fig. 1. Calidris alpina. Dunlin capturing a polychaete at the study site, Banzu intertidal sandflat in Tokyo Bay, Japan. Photocredit: Mitsuru Tamura

greater foraging effort to the successful mode, and (2) the birds shift their foraging mode in response to changing prey availability and sediment penetrability driven by the tidal cycle.

\section{MATERIALS AND METHODS}

Study site. The Banzu intertidal sandflat $\left(35^{\circ} 24.8^{\prime} \mathrm{N}\right.$, $139^{\circ} 53.9^{\prime} \mathrm{E}$ ) is located on the east coast of Tokyo Bay and covers an area of $7.6 \mathrm{~km}^{2}$ (Fig. 2). Tides are semidiurnal with amplitudes from 0.5 to $1.6 \mathrm{~m}$. The slope of the seabed at the site is gentle (ca. 1/1400). The observation area has the highest elevation and, consequently, both the longest sediment emersion time and shorebird use time on the Banzu sandflat. There is no macrovegetation in the observation area, although marsh plants, comprised mainly of the common reed Phragmites australis (Cav.), are present along the shore. Dunlin are common overwintering small shorebirds on intertidal flats around Japan. The study site supports a mean of ca. 1200 with a peak up to 2000 dunlin during the overwintering period (T. Kuwae unpubl. data).

We defined 2 sites based on prey abundance: Site A was located along the edge of the shore and comprised an area 0 to $10 \mathrm{~m}$ away from the shore $\times$ ca. $100 \mathrm{~m}$ along the shore; Site B was further from the shore, and comprised an area 10 to $80 \mathrm{~m}$ from the shore $\times$ ca. $100 \mathrm{~m}$ along the shore (Fig. 2). Sediment characteristics and prey density were examined at each site on the middle days of the foraging observation periods (29 January 2003 and 20 January 2004, Kuwae 2007). Briefly, sediments at both sites were characterized by well-sorted fine sand with a median grain size of 220 to $270 \mu \mathrm{m}$. However, Site A had higher silt and clay content $(4 \%)$ and total organic carbon content $(0.29 \%)$ than Site B (1 and $0.06 \%$, respectively). Nereidid poly- 


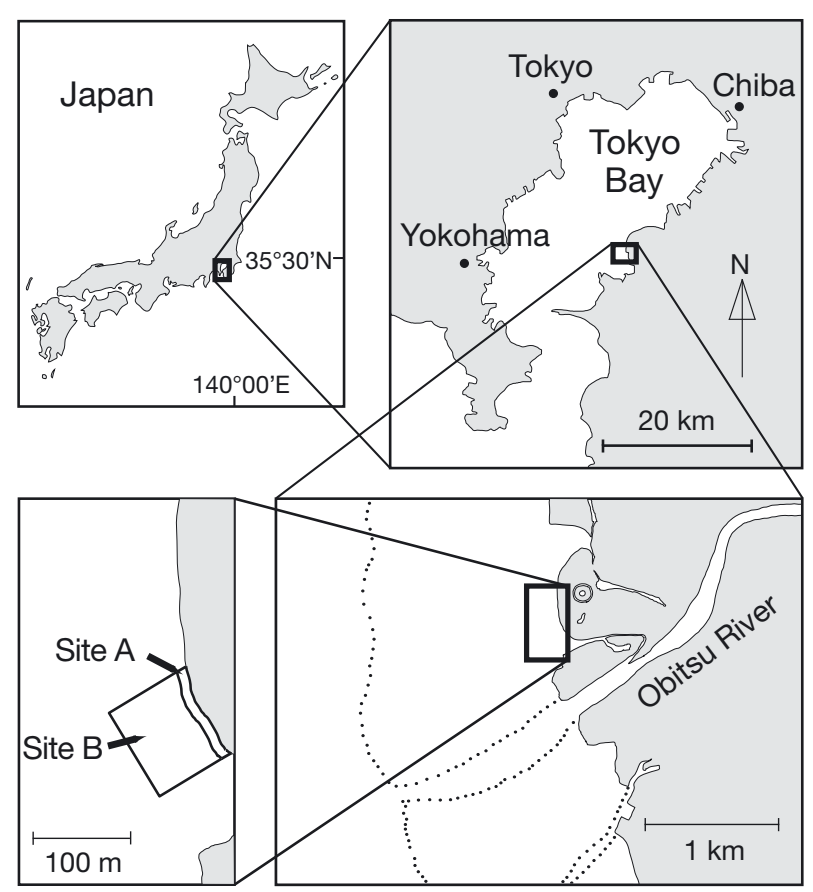

Fig. 2. Location of the study site, Banzu intertidal sandflat, Tokyo Bay, Japan. Dotted lines indicate the lowest tidal level

chaetes Hediste sp. and Ceratonereis erythraeensis (Fauvel) and the ocypodid sand bubbler crab Scopimera globosa (De Haan) were dominant macroinvertebrates and the captured prey species determined by video sequences at the site; their combined densities were more than 10 -fold higher at Site $\mathrm{A}$ (mean $\pm \mathrm{SE}$, $909 \pm 177$ ind. $\left.\mathrm{m}^{-2}, \mathrm{n}=8\right)$ than at Site B $(65 \pm 43$ ind. $\mathrm{m}^{-2}, \mathrm{n}=8$ ). The other dominant macroinvertebrates that were not captured by dunlin included batillariid gastropods (130 \pm 82 ind. $\left.\mathrm{m}^{-2}, \mathrm{n}=16\right)$ and ungulid bivalves $\left(520 \pm 184\right.$ ind. $\left.\mathrm{m}^{-2}, \mathrm{n}=16\right)$. The amphipod Corophium, which is a major food source for small shorebirds (Hicklin \& Smith 1984), was not observed; further, other microinvertebrates (sizes up to several millimeters) were much less abundant than macroinvertebrates at the site. Independent data for the variability of macroinvertebrate densities and geophysical conditions at greater spatial scales within the studied sandflat have been reported elsewhere (Kuwae et al. 1998, 2003, 2006, Sassa \& Watabe 2007, 2008).

We performed fieldwork throughout new-moon spring tidal emersion periods during the day from 27 to 31 January 2003 and 19 to 23 January 2004. Potential predation danger for dunlin appears low at the site as no falcons were observed during the study period.

Behavioral observations. We quantified foraging action and prey capture using a video image system that affords a variety of advantages over the conventional focal observation technique, including reanaly- sis and high magnification capability. We used a digital camcorder (Canon, XL1S) with a telephoto zoom lens (Canon, EF 100-400 mm f/4.5-5.6L IS USM) or a mono-focal telephoto lens (Canon, EF $400 \mathrm{~mm} \mathrm{f/2.8L} \mathrm{IS}$ USM) through a lens adaptor (Canon, EF Adaptor XL), with a tripod several meters landward from the shore. We used a focus length extension lens (Canon, Extender EF $1.4 \times$ II or $\times$ EF $2.0 \times$ II) as required for high magnification, e.g. observations for Site B from the shore. Video images with a focal length of 720 to $5760 \mathrm{~mm}$ (20.6 to $164.6 \times$ optical magnification) were achieved by this system, making it possible to detect microinvertebrates. We replayed and analyzed the recorded video images using slow-motion and stop-motion replay modes to analyze the rapid feeding actions of dunlin, which are usually completed within $0.2 \mathrm{~s}$. We randomly selected individuals for video recording. Although the individuals were unmarked, video images analyses of bill and tarsus morphology and plumage patterns made individual identification possible and circumvented pseudoreplication. We used only images that were sufficiently magnified and sharp to resolve dunlin feeding on small prey for data analysis.

We classified the foraging behavior of dunlin as pecking (a single touch of the bill tip to the sediment surface) or probing (a single insertion of the bill tip into the sediment and retraction, or rapid multiple movements with the bill tip below the sediment surface). We calculated foraging action rate as the number of actions per unit foraging time. Non-foraging time, including resting, vigilance against aircraft (an airport is near the study site), and interference competition (scarce) were deducted from total observation duration to yield foraging time. We continuously tracked each individual, resulting in the mean observation time per individual being $1.7 \pm 0.2 \mathrm{~min}(\mathrm{n}=168)$.

Determination of intake rates. We measured bill length and the size of prey on capture (stretched length of polychaetes and carapace width of crabs) by video image analysis using tarsus length $(26 \mathrm{~mm})$ (Prater et al. 1977) as a standard length. We collected prey items (polychaetes Hediste sp. and Ceratonereis erythraeensis, and sand bubbler crab Scopimera globosa) from the site and determined the relationships between stretched body length and dry mass for the polychaetes and carapace width and dry mass for the crabs. We powdered part of the collected samples for analyses of energy (polychaetes: $\mathrm{n}=14$, crabs: $\mathrm{n}=5$ ), carbon (polychaetes: $n=34$, crabs: $n=23$ ), and nitrogen content (polychaetes: $\mathrm{n}=34$, crabs: $\mathrm{n}=23$ ). We measured energy content using a bomb calorimeter (CA-4PJ, Shimadzu). Following acidification of the samples using $1 \mathrm{M} \mathrm{HCl}$ to eliminate carbonates, we measured total organic carbon content and total nitrogen content using an elemental analyzer (Flash EA 
1112, Thermo Electron). Using the measured size of captured prey, the size-mass relationships, and massbased energetic and nutritional contents, we determined energy- and nutrition-based intake rates.

Environmental parameters. Air temperature and wind speed were monitored hourly ca. $3.0 \mathrm{~km}$ north of the study site by the Japan Meteorological Agency. We estimated wind speed at the site based on these data according to Davenport (1961), following confirmation of the applicability using intermittently obtained data at the site. Receding tides were continuously monitored using the video systems, and the time of emersion for each tide was visually determined from the video images.

Sediment hardness was measured according to Sassa \& Watabe $(2007,2008)$. We measured the vane shear strength of the sediment surface (depth: 0 to $4 \mathrm{~cm}$ ) as an index of sediment hardness, using a pocket shear vane gauge (Model SH-63B, Maruto Testing Machine). The gauge had 2 intersecting vane blades; the dimensions of each blade were $20 \mathrm{~mm}$ in width, $40 \mathrm{~mm}$ in height, and $0.8 \mathrm{~mm}$ in thickness. The rotational shearing speed of the vane blades in the sediment was controlled to be below $60^{\circ} \mathrm{min}^{-1}$. The accuracy was estimated to be $\pm 0.2 \mathrm{kPa}$, which was confirmed by separately measuring the strength of the sediment at a nearby point. The discretely measured data were then converted into continuous data using continuously observed data on the temporal changes in suction after emersion (Sassa \& Watabe 2008) and the suction versus vane shear strength relationship at the site (Sassa \& Watabe 2007).

Statistical analyses. We used a generalized linear model with a logit link function to examine the effect of site (Site A versus Site B, categorical data), Time after emersion (continuous data), Temperature (continuous data), and Wind speed (continuous data) on the percentage of pecking to total actions (pecking + probing). A priori selection of candidate models was based on the principle of parsimony and scientific plausibility (Burnham \& Anderson 2002). We fitted the global model with all explanatory variables (Site, Time after emersion, Temperature, and Wind) (Pienkowski 1983, Piersma 1987, McNeil et al. 1992) and the second order interactions except for continuous variables $\times$ continuous variables.

We used Akaike's information criterion (AIC) to compare the fits of candidate models. We selected a quasibinomial error distribution for the model structure because the global model was overdispersed. Since the ratio of the sample size to number of predictor variables in the global model was $<40$, we used the biascorrected AIC $\left(\right.$ QAIC $\left._{C}\right)$ (Hurvich \& Tsai 1989, Burnham $\&$ Anderson 2002). The best fitting model has the smallest $\mathrm{AIC}\left(\mathrm{AIC}_{\min }\right)$, and the difference in AIC values between models indicates the relative support for the models. Therefore, for model $i$, the AIC difference $\left(\Delta_{i}\right)$ was calculated as: $\mathrm{AIC}_{i}-\mathrm{AIC}_{\min }$.

Since the best fitting model is often highly variable and thus has uncertainty, inference based on a single best fitting model can cause bias. To reduce model selection bias, we implemented multimodel inference using a confidence set of models (Burnham \& Anderson 2002). We selected a confidence set to include only the candidate models with $\Delta_{i}<4$, because models with $\Delta_{i}>4$ are considerably less likely to approximate the true model (Burnham \& Anderson 2002).

We calculated an Akaike weight $\left(w_{i}\right)$ according to Burnham \& Anderson (2002) to interpret the relative likelihood of a model in confidence sets; $w_{i}$ is the probability that model $i$ would be selected as the best fitting model in the confidence set. We calculated selection probability for predictor variables by summing $w_{i}$ across all the models in the confidence set. In the present study, we considered the predictor variables with a selection probability $>0.9$ to be strongly supported by the models. We performed all statistical analyses using R 2.1.1 (R Development Core Team 2005).

\section{RESULTS}

\section{Environmental parameters and captured prey}

There was no rainfall during the observation period. Temperature and wind speed ranged from -3.1 to $11.6^{\circ} \mathrm{C}$ and 0.0 to $7.2 \mathrm{~m} \mathrm{~s}^{-1}$, respectively. The time of emersion was ca. $0.6 \mathrm{~h}$ longer at Site B than Site A for each tide. The maximum time of emersion at Site B was $6.9 \mathrm{~h}$. Sediment hardness increased with increasing time after emersion $(0.6 \mathrm{kPa}$ at the onset of emersion and $2.3 \mathrm{kPa} 7 \mathrm{~h}$ after emersion).

Prey items consumed by dunlin in all the video sequences were identified as nereidid polychaetes, either Hediste sp. or Ceratonereis erythraeensis $(82.9 \%, \mathrm{n}=92)$, sand bubbler crabs Scopimera globosa $(16.2 \%, \mathrm{n}=18)$, and macroalgae Ulva sp. $(0.9 \%, \mathrm{n}=1)$; no other prey items, including microinvertebrates, were identified. Dunlin foraging actions showed no indication of surface tension feeding (bolus transport from bill tip to buccal cavity by increasing the bill opening) or biofilm grazing (slow advance and bolus segregation by opening and closing the bill). Polychaetes had a width of $<1 \mathrm{~mm}$ and a mean $( \pm \mathrm{SD})$ stretched body length of $46.2 \pm 39.7 \mathrm{~mm}(\mathrm{n}=43)$ when captured by pecking and $32.2 \pm 28.5 \mathrm{~mm}(\mathrm{n}=49)$ when captured by probing, showing no significant difference in length between the 2 foraging modes (Mann-Whitney $U$-test, $U=1253, \mathrm{p}=0.119)$. Crabs had a carapace width of $4.1 \pm 2.0 \mathrm{~mm}(\mathrm{n}=9)$ when captured by peck- 
ing and $3.8 \pm 1.7 \mathrm{~mm}(\mathrm{n}=9)$ when captured by probing, showing no significant difference in width between modes $(U=43, \mathrm{p}=0.863)$.

Obtained relationships between prey size $(\mathrm{L}, \mathrm{mm}$, stretched length for polychaetes and carapace width for crabs) and their dry mass (DM, mg) were well fitted with the power function: $\mathrm{DM}=a \mathrm{~L}^{b}$, where $a=0.0061$ and $b=1.8874$ for the polychaetes $\left(\mathrm{r}^{2}=0.72, \mathrm{n}=129\right)$ and $a=0.4545$ and $b=2.8457$ for the crabs $\left(r^{2}=0.94\right.$, $\mathrm{n}=88$ ). The dry mass of captured crabs was estimated to be higher than that of the polychaetes, whereas polychaetes were both energetically and nutritionally richer than the crabs on the basis of dry mass (Table 1).

There was no indication of specialization in captured prey items between foraging modes; i.e. no significant difference in captured prey ratio (polychaete/crab) between the 2 modes (Wilcoxon matched-pair signedrank test, $W=3043, \mathrm{p}=0.217, \mathrm{n}=41$ ).

\section{Foraging behavior}

Foraging action rate by pecking was significantly higher than that by probing at both Site A ( $W=61$, p < $0.0001)$ and Site B ( $W=2437, \mathrm{p}<0.0001)$ (Fig. 3a). Success rate by pecking was lower at both sites, but the difference was only significant at Site B (Site B: $W=$ 22 576, $\mathrm{p}=$ 0.027; Site A: $W=1286, \mathrm{p}=0.089$ ) (Fig. 3b). There was no significant difference in capture rate between pecking and probing at either site (Site A: $W=371, \mathrm{p}=0.615 ;$ Site $\mathrm{B}: W=6806, \mathrm{p}=0.216$ ) (Fig. 3c). Further, there were no significant differences in intake rate between pecking and probing at either site for energy (Site A: $W=372, \mathrm{p}=0.632$; Site B: $W=$ 6829, $\mathrm{p}=0.187$ ), carbon (Site $\mathrm{A}: W=372, \mathrm{p}=0.632$; Site $\mathrm{B}: W=6830, \mathrm{p}=0.186$ ), or nitrogen (Site $\mathrm{A}: W=$ 372, $\mathrm{p}=0.632$; Site B: $W=6829, \mathrm{p}=0.187$ ) (Fig. 3d).

The frequency distribution of the percentage of pecking to total actions $\left(\mathrm{POP}_{\mathrm{ta}}\right)$ for the studied population showed a unimodal shape, with a mean \pm SD value of $70.4 \pm 17.8 \%$ (Fig. 4), indicating no strong intrapopulation specialization in foraging mode. Further, there were no significant relationships between $\mathrm{POP}_{\text {ta }}$ and bill length (Spearman's rank correlation, $S=12982, \mathrm{r}^{2}=0.02, \mathrm{p}=0.415, \mathrm{n}=$ $41)$, between the percentage of pecking to total captures $\left(\mathrm{POP}_{\mathrm{tc}}\right)$ and bill length $\left(S=10395, \mathrm{r}^{2}=0.009, \mathrm{p}=0.557\right.$, $\mathrm{n}=41$ ), or between the percentage of pecking to total energy intake $\left(\mathrm{POP}_{\text {tei }}\right)$ and bill length $\left(S=13251, \mathrm{r}^{2}=0.02\right.$, $\mathrm{p}=0.335, \mathrm{n}=41$ ).

We calculated normalized $\mathrm{POP}_{\text {ta }}$ as individual $\mathrm{POP}_{\mathrm{ta}} /$ median value $(73.0 \%)$
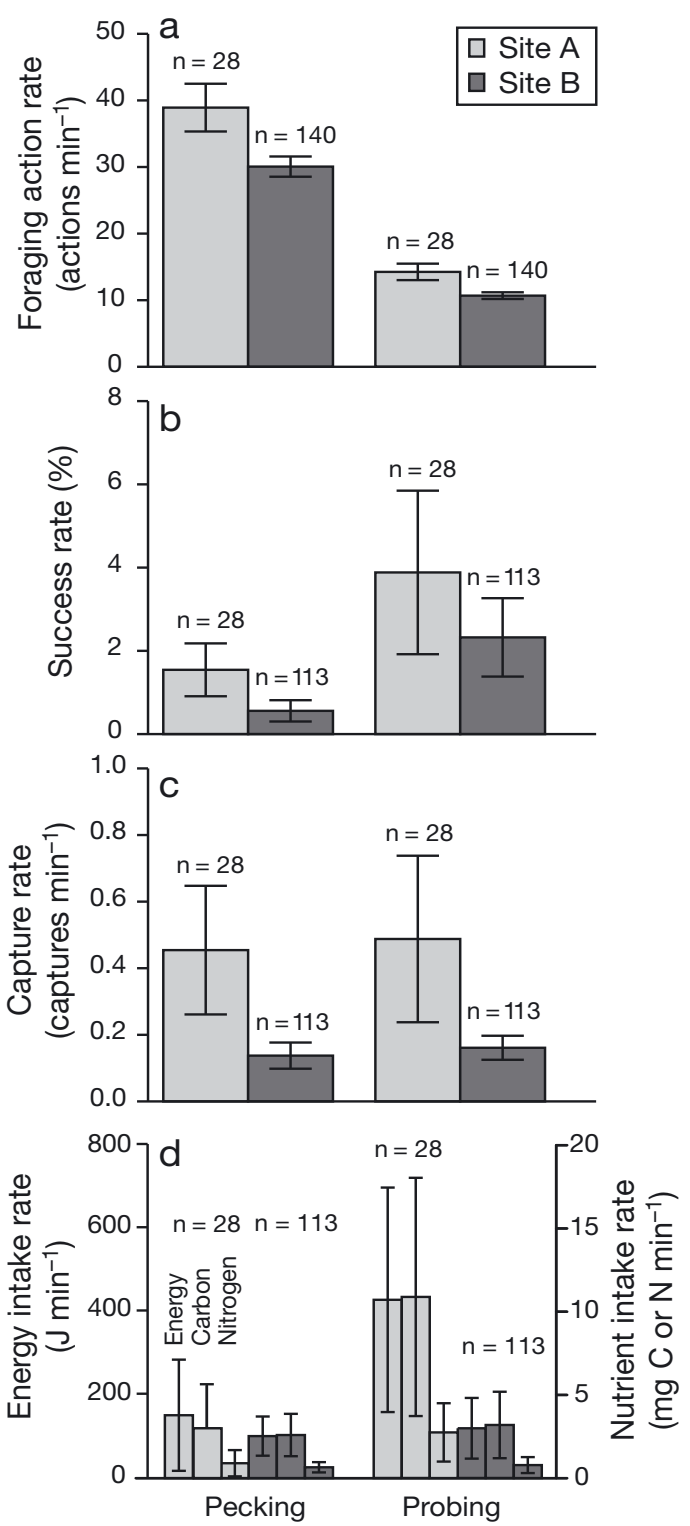

Fig. 3. Calidris alpina. (a) Foraging action rate, (b) success rate, (c) capture rate, and (d) intake rate for pecking and probing foraging modes in dunlin at Sites A and B. Errors bars are $\pm \mathrm{SE}$

Table 1. Calidris alpina. Dry mass (DM) and energy, carbon, and nitrogen content (mean \pm SD) of captured prey items of dunlin

\begin{tabular}{|lcccc|}
\hline Captured prey & Polychaetes & Crabs & $U$ & $\mathrm{p}$ \\
\hline Dry mass (mg ind ${ }^{-1}$ ) & $10.0 \pm 16.8$ & $35.9 \pm 48.1$ & 329 & $<0.0001$ \\
$\mathrm{n}$ & 92 & 18 & & \\
Energy $\left(\mathrm{kJ} \mathrm{g}^{-1} \mathrm{DM}\right)$ & $21.0 \pm 1.9$ & $11.4 \pm 0.4$ & 70 & 0.0002 \\
$\mathrm{n}$ & 14 & 5 & & \\
Carbon $\left(\mathrm{mg} \mathrm{C} \mathrm{g}^{-1} \mathrm{DM}\right)$ & $416.1 \pm 18.8$ & $311.6 \pm 18.3$ & 782 & $<0.0001$ \\
$\mathrm{n}$ & 34 & 23 & & \\
Nitrogen $\left(\mathrm{mg} \mathrm{N} \mathrm{g}^{-1} \mathrm{DM}\right)$ & $124.0 \pm 7.8$ & $69.6 \pm 4.6$ & 782 & $<0.0001$ \\
$\mathrm{n}$ & 34 & 23 & & \\
\hline
\end{tabular}




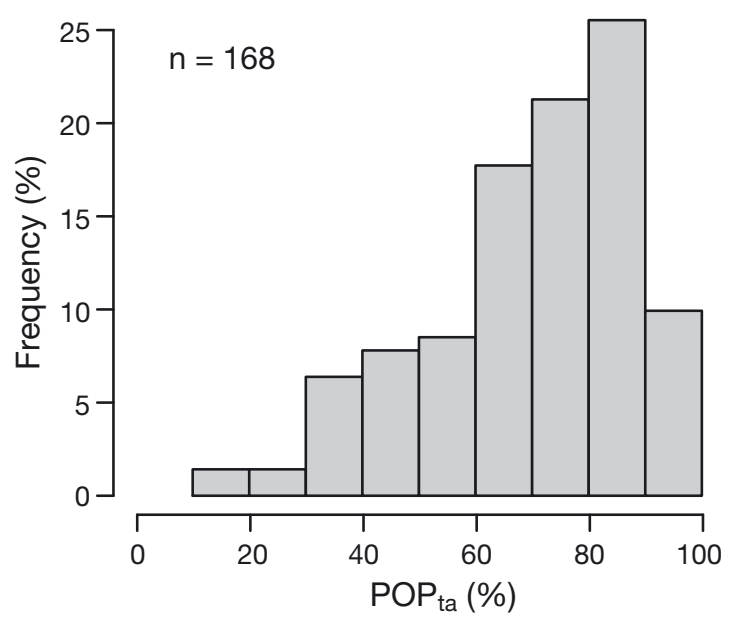

Fig. 4. Calidris alpina. Frequency distribution of the percentage of pecking to total actions $\left(\mathrm{POP}_{\mathrm{ta}}\right)$ for the studied population of dunlin

of $\mathrm{POP}_{\mathrm{ta}}$ for the studied population (see Fig. 4) to show the relative pecking preference for each individual within the population. Individuals that use pecking relatively more than other individuals are indicated by values $>1$. There were positive relationships between normalized $\mathrm{POP}_{\mathrm{ta}}$ and $\mathrm{POP}_{\mathrm{tc}}$ (Spearman's rank correlation, $S=4931, \mathrm{r}^{2}=0.33, \mathrm{p}<0.0001, \mathrm{n}=41$ ) (Fig. 5a) and between normalized $\mathrm{POP}_{\text {ta }}$ and $\mathrm{POP}_{\text {tei }}\left(S=5326, \mathrm{r}^{2}=\right.$ $0.29, \mathrm{p}<0.0003, \mathrm{n}=41$ ) (Fig. 5b), i.e. individuals that allocated relatively more foraging effort to pecking attained a proportionate higher feeding success by pecking, and vice versa.

The model selection results for $\mathrm{POP}_{\mathrm{ta}}$ strongly supported only the positive effect of Time after emersion (selection probability: 1.00) (Table 2, Fig. 6). The model poorly supported other predictor variables (Site, Temperature, and Wind; selection probability: 0.03 to 0.69 ).

\section{DISCUSSION}

\section{Choice of foraging mode}

Given trade-offs between the benefits and costs of various foraging modes, multimodal foragers choose one of the alternative modes (Bautista et al. 2001). Our results showed that probing was significantly more successful than pecking at Site B (but not at Site A, probably due to low detection power arising from the small sample size) (Fig. 3b), attributable to the higher prey availability potential within the extended search depths (Myers et al. 1980, Mouritsen \& Jensen 1992). However, probing may cost more than pecking with respect to foraging time, energy expenditure, and risk of bill wear due to penetration of the bill into sediments (Le V. dit Durell 2000), resulting in lower foraging
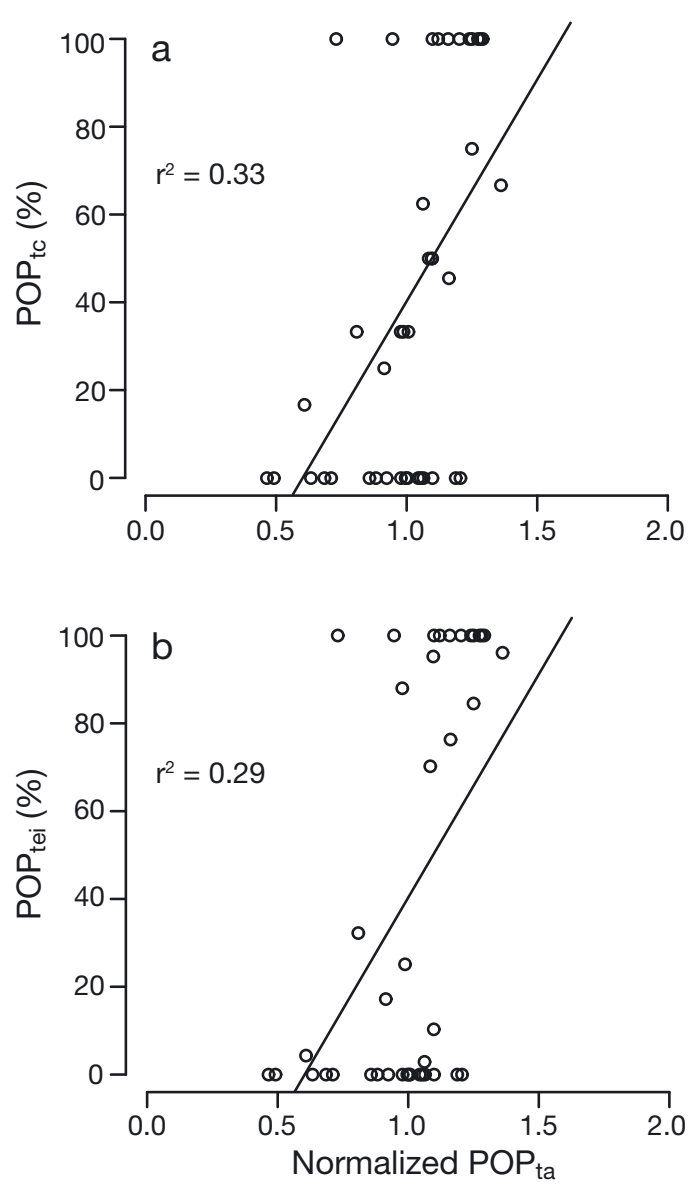

Fig. 5. Calidris alpina. (a) Percentage of pecking to total captures $\left(\mathrm{POP}_{\mathrm{tc}}\right)$ versus normalized percentage of pecking to total actions $\left(\mathrm{POP}_{\mathrm{ta}}\right)$ and $(\mathrm{b})$ percentage of pecking to total energy intake $\left(\mathrm{POP}_{\text {tei }}\right)$ versus normalized $\mathrm{POP}_{\text {ta }}$. Normalized $\mathrm{POP}_{\text {ta }}$ was calculated as individual $\mathrm{POP}_{\mathrm{ta}} /$ median value $(73.0 \%)$ of $\mathrm{POP}_{\mathrm{ta}}$ for the studied population (see Fig. 4). Individuals that used pecking relatively more than other individuals are indicated by values $>1$. Most data plots scattered at either 0 or $100 \%$ on the $y$-axes are due to small sample sizes $(\mathrm{n}=1)$ from which the percentages were calculated, which generated lower $r^{2}$ values (but were still significant for both relationships)

action rate than pecking (Fig. 3a). As a consequence of this trade-off in choice of foraging mode, dunlin appeared to benefit equally, as indicated by capture and intake rates, from pecking and probing (Fig. 3c). No significant difference in captured prey ratio (polychaete/crab) between the 2 modes suggests no significant difference in availability between the 2 modes, although detectability may be highly different considering the size and shape of these prey items.

Positive relationships between normalized $\mathrm{POP}_{\mathrm{ta}}$ and $\mathrm{POP}_{\mathrm{tc}}$ (Fig. 5a) and between normalized $\mathrm{POP}_{\mathrm{ta}}$ and $\mathrm{POP}_{\text {tei }}$ (Fig. 5b) indicate an efficient deployment of the selected foraging mode, i.e. individuals that allocate more foraging effort to pecking attain proportionate 
Table 2. Model selection results for the percentage of pecking to total actions $\left(\mathrm{POP}_{\mathrm{ta}}\right)$ of dunlin Calidris alpina. Predictor variables included in the selected models are shown with an $\times$. TAE: time after emersion; Temp: temperature; QAIC $_{C}$ : bias-corrected Akaike's information criterion; $\Delta_{i}$ : AIC difference calculated as $\mathrm{AIC}_{i}-\mathrm{AIC}_{\text {min }}$ (the model with the lowest $\Delta_{i}$ is the best fitting model); $w_{i}$ : Akaike weight showing the probability that model $i$ would be selected as the best fitting model in the confidence set

\begin{tabular}{|c|c|c|c|c|c|c|c|c|c|c|}
\hline Model & TAE & Site & Temp & Wind & $\begin{array}{c}\text { Site } \times \\
\text { TAE }\end{array}$ & $\begin{array}{l}\text { Site } \times \\
\text { Temp }\end{array}$ & $\begin{array}{l}\text { Site } \times \\
\text { Wind }\end{array}$ & $\mathrm{QAIC}_{\mathrm{C}}$ & $\Delta_{i}$ & $w_{i}$ \\
\hline 1 & $x$ & $x$ & $\times$ & & & & & 254.03 & 0 & 0.16 \\
\hline 2 & $x$ & $x$ & & & & & & 254.44 & 0.41 & 0.13 \\
\hline 3 & $\times$ & $\times$ & & $x$ & & & & 255.19 & 1.16 & 0.09 \\
\hline 4 & $x$ & & $x$ & & & & & 255.19 & 1.16 & 0.09 \\
\hline 5 & $x$ & $x$ & $x$ & $x$ & & & & 255.24 & 1.21 & 0.09 \\
\hline 6 & $x$ & & & & & & & 255.26 & 1.22 & 0.09 \\
\hline 7 & $x$ & & & $\times$ & & & & 255.60 & 1.56 & 0.07 \\
\hline 8 & $x$ & & $x$ & $x$ & & & & 255.99 & 1.96 & 0.06 \\
\hline 9 & $x$ & $\times$ & $x$ & & & $\times$ & & 256.21 & 2.18 & 0.05 \\
\hline 10 & $x$ & $x$ & & & $x$ & & & 256.32 & 2.29 & 0.05 \\
\hline 11 & $x$ & $x$ & $x$ & $\times$ & & & $\times$ & 257.14 & 3.10 & 0.03 \\
\hline 12 & $x$ & $x$ & & $x$ & $\times$ & & & 257.22 & 3.19 & 0.03 \\
\hline 13 & $x$ & $\times$ & $x$ & $\times$ & $\times$ & & & 257.26 & 3.23 & 0.03 \\
\hline 14 & $x$ & $x$ & $x$ & $x$ & & $x$ & & 257.45 & 3.41 & 0.03 \\
\hline $\begin{array}{l}\text { Selection } \\
\text { probability }\end{array}$ & 1 & 0.69 & 0.54 & 0.43 & 0.11 & 0.08 & 0.03 & & & \\
\hline
\end{tabular}

capture rate and intake rate by pecking, and vice versa. Possible bases for this result may include, variously (1) obligate individual specialization in foraging mode, or (2) a more generalist strategy, continuously assessing and adjusting mode against varying prey availability. Individual specialization in foraging behavior is common in shorebirds and often associated with differences in morphology or intrinsically acquired skills (Le V. dit Durell 2000). However, this prediction appears not to be the case here since individual specialization in foraging mode, as would be indicated by a bimodal distribution in $\mathrm{POP}_{\mathrm{ta}}$, was not observed in the present study (Fig. 4). Furthermore, bill length was

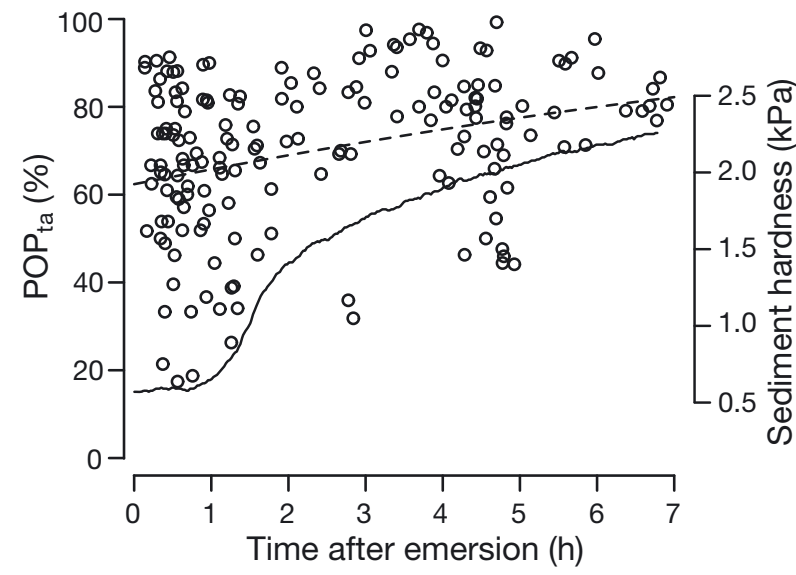

Fig. 6. Calidris alpina. Percentage of pecking to total actions $\left(\mathrm{POP}_{\mathrm{ta}}\right)$ versus time after emersion. Dashed line is the relationship supported by a generalized linear model (Table 2). Superimposed solid line indicates a change in sediment hardness (vane shear strength) at the study site not significantly related to any of the indices of foraging behavior $\left(\mathrm{POP}_{\mathrm{ta}}, \mathrm{POP}_{\mathrm{tc}}\right.$, or $\left.\mathrm{POP}_{\text {tei }}\right)$, which suggests there are no obvious morphological effects on foraging mode. We were unable to completely exclude the possibility of some degree of foraging specialization due to inter- and intrapopulation variation, as the frequency distribution of $\mathrm{POP}_{\text {ta }}$ was relatively skewed to the pecking-dominance side. Relative foraging mode and grain size preferences can differ between species and/or populations; however, we believe that this skew resulted mainly from foraging generalists' adaptation and flexibility in foraging mode choice, induced by environmental constraints at their foraging sites. Therefore, we conclude that the birds appropriately choose and shift their foraging mode to attain higher intake rates, but we did not experimentally show that the shift was optimal and supports optimal foraging theory (i.e. the birds maximized intake rate or minimized energetic cost for foraging by mode shift). Foraging mode decision would be equally crucial to patch and prey item decisions for foragers' fitness. The present study provides empirical evidence of an appropriate adjustment in foraging mode for successful feeding and can extend the ideal forager model for patch choice (van Gils et al. 2006) into foraging mode choice.

\section{Response to varying environmental conditions}

As expected, dunlin shifted foraging mode in response to changes in environmental conditions. Dunlin increased $\mathrm{POP}_{\text {ta }}$ as time increased after emersion (Table 2, Fig. 6). The environmental conditions chang- 
ing with time after emersion, by inference, include (1) prey migration (Dierschke et al. 1999) and/or prey activity (Esselink \& Zwarts 1989), induced by sediment desiccation, and (2) sediment penetrability (Hryciw \& Dowding 1987, Sassa \& Watabe 2007). These factors may generally be closely intertwined and affect shorebirds' prey availability and foraging behavior. Thus tide-induced foraging mode shift may be expected in response to changes in prey availability with sediment depth. However, this notion would appear not be the case for the following 2 reasons. (1) If dunlin did adjust their foraging mode in response to the redistribution of polychaetes into deeper layers, $\mathrm{POP}_{\text {ta }}$ would be expected to decrease with increasing time after emersion; however, $\mathrm{POP}_{\text {ta }}$ increased. (2) Water content at the site shows no significant variation with tidal level (Kuwae et al. 2003). However, a decrease in the penetrability of intertidal sediments with time after emersion is a well-known hydrological process explained by tide-induced dropping of the water table, which results in the development of suctions and thereby increases effective confining pressures in the sediment surface layer (Hryciw \& Dowding 1987, Sassa \& Watabe 2007). Indeed, sediment hardness (as shown by vane shear strength) at $7 \mathrm{~h}$ after emersion $(2.3 \mathrm{kPa}$, Fig. 6) was ca. 4 times higher than that at the onset of emersion $(0.6 \mathrm{kPa})$. The birds can benefit from both feeding modes when sediment is less hard at the onset of emersion, as shown by scattered POP $_{\text {ta }}$ data points in all ranges (Fig. 6). However, with increased time after emersion, firmer sediments can cause a reduction in mode choice flexibility and would be attributable to concentrated $\mathrm{POP}_{\text {ta }}$ data points around $80 \%$ at $7 \mathrm{~h}$ after emersion (Fig. 6). Therefore, the observed shift from probing to pecking is likely to be based on a response to an environmental constraint rather than prey availability per se.

Overall, our findings highlight a short time-scale (within one tide), individual-based foraging adaptation to changes in environmental conditions within the same patch by a foraging generalist. This may add new understanding to the well-known preference by shorebirds (population-based) for high-penetrability patches (Myers et al. 1980, Gerritsen \& van Heezik 1984, Mouritsen \& Jensen 1992). There are a variety of advantages for foraging generalists; however, these are particularly underscored in habitats such as intertidal flats, where environmental conditions are rapidly and drastically changing.

Worldwide declines in shorebird populations (Wetlands International 2006) fuel the need for improved understanding of their foraging behavior and feeding ecology. We anticipate that constraints on foraging mode can narrow the range of available prey items and weaken resource partitioning between and within spe- cies (Le V. dit Durell 2000). Thus our findings of sediment hardness as an environmental constraint for dunlin suggest that conservation and restoration of softbottom intertidal habitats, such as mudflats, may be particularly critical for probing shorebirds. Although the relative importance of habitat values for shorebirds varies according to different trade-offs between rewards and costs (e.g. Warnock et al. 2002), for probing shorebirds, decreased utility of the probing foraging mode given harder sediments can result in a reduction in fitness due to competition with plovers (Rojas et al. 1999) Finally, the importance of mudflats as feeding habitat may be enhanced by surficial biofilm, recently recognized as an important dietary constituent for a small shorebird (Kuwae et al. 2008), since biofilm develops most richly over muddy, lowenergy intertidal and estuarine systems where sediment resuspension by hydrodynamic forcing is low.

Acknowledgements. We thank A. Kuwae for video image analysis; M. Yoshikawa for chemical analysis; and R. W. Elner, K. J. Mathot, and 4 anonymous reviewers for helpful comments on the manuscript. N. Warnock provided additional insights. This work was supported by the Japan Society for the Promotion of Science (JSPS) Postdoctoral Fellowships for Research Abroad (FY2004 to T.K.) and the Japanese Ministry of Education, Culture, Sports, Science and Technology (MEXT) Grant-in-Aid for Young Scientists (A) (20681023 to T.K.).

\section{LITERATURE CITED}

Baker MC, Baker AEM (1973) Niche relationships among six species of shorebirds on their wintering and breeding ranges. Ecol Monogr 43:193-212

Bautista LM, Tinbergen J, Kacelnik A (2001) To walk or to fly? How birds choose among foraging modes. Proc Natl Acad Sci USA 98:1089-1094

Burnham KP, Anderson DR (2002) Model selection and multimodel inference: a practical information-theoretic approach. Springer, New York

Burton PJK (1974) Feeding and the feeding apparatus in waders. British Museum of Natural History, London

Davenport AG (1961) The spectrum of horizontal gustiness near the ground in high winds. Q J R Meteorol Soc 87: $194-221$

Dierschke V, Kube J, Rippe H (1999) Feeding ecology of dunlin Calidris alpina staging in the southern Baltic Sea, 2. Spatial and temporal variations in the harvestable fraction of their favorite prey Hediste diversicolor. J Sea Res 42: $65-82$

> Elner RW, Beninger PG, Jackson DL, Potter TM (2005) Evidence of a new feeding mode in western sandpiper (Calidris mauri) and dunlin (Calidris alpina) based on bill and tongue morphology and ultrastructure. Mar Biol 146: 1223-1234

Esselink P, Zwarts L (1989) Seasonal trend in burrow depth and tidal variation in feeding activity of Nereis diversicolor. Mar Ecol Prog Ser 56:243-254

Estrella SM, Masero JA, Pérez-Hurtado A (2007) Small-prey profitability: field analysis of shorebirds' use of surface tension of water to transport prey. Auk 124:1244-1253 
Fausch KD, Nakano S, Kitano S (1997) Experimentally induced foraging mode shift by sympatric charrs in a Japanese mountain stream. Behav Ecol 8:414-420

Gerritsen AFC, van Heezik YM (1984) Substrate preference and substrate related foraging behaviour in three Calidris species. Neth J Zool 35:671-692

Grant J (1984) Sediment microtopography and shorebird foraging. Mar Ecol Prog Ser 19:293-296

Helfman GS, Winkelman DL (1991) Energy trade-offs and foraging mode choice in American eels. Ecology 72:310-318

> Hicklin PW, Smith PC (1984) Selection of foraging sites and invertebrate prey by migrant semipalmated sandpiper Calidris pusilla (Pallas) in the Minas Basin, Bay of Fundy. Can J Zool 62:2201-2210

Hryciw RD, Dowding CH (1987) Cone penetration of partially saturated sands. Geotech Test J 10:135-141

Hurvich CM, Tsai CL (1989) Regression and time series model selection in small samples. Biometrika 76:297-307

Kuwae T (2007) Diurnal and nocturnal feeding rate in Kentish plovers Charadrius alexandrinus on an intertidal flat as recorded by telescopic systems. Mar Biol 151:663-673

Kuwae T, Hosokawa Y, Eguchi N (1998) Dissolved inorganic nitrogen cycling in Banzu intertidal sand-flat, Japan. Mangrove Salt Marsh 2:167-175

Kuwae T, Kibe E, Nakamura Y (2003) Effect of emersion and immersion on the porewater nutrient dynamics of an intertidal sandflat in Tokyo Bay. Estuar Coast Shelf Sci 57: 929-940

Kuwae T, Kamio K, Inoue T, Miyoshi E, Uchiyama Y (2006) Oxygen exchange flux between sediment and water in an intertidal sandflat, measured in situ by the eddy-correlation method. Mar Ecol Prog Ser 307:59-68

Kuwae T, Beninger PG, Decottignies P, Mathot KJ, Lund DR, Elner RW (2008) Biofilm grazing in a higher vertebrate: the western sandpiper, Calidris mauri. Ecology 89: 599-606

Le V. dit Durell SEA (2000) Individual feeding specialisation in shorebirds: population consequences and conservation implications. Biol Rev Camb Philos Soc 75:503-518

Lister BC, Aguayo AG (1992) Seasonality, predation, and the behaviour of a tropical mainland anole. J Anim Ecol 61:717-733

McNeil R, Drapeau P, Goss-Custard JD (1992) The occurrence and adaptive significance of nocturnal habits in waterfowl. Biol Rev Camb Philos Soc 67:381-419

Mouritsen KN, Jensen KT (1992) Choice of microhabitat in tactile foraging dunlins Calidris alpina: the importance of sediment penetrability. Mar Ecol Prog Ser 85:1-8

> Myers JP, Williams SL, Pitelka FA (1980) An experimental analysis of prey availability for sanderlings (Aves:

Editorial responsibility: Hans Heinrich Janssen,

Oldendorf/Luhe, Germany
Scolopacidae) feeding on sandy beach crustaceans. Can J Zool 58:1564-1574

> Nebel S, Thompson GJ (2005) Foraging behaviour of western sandpipers changes with sediment temperature: implications for their hemispheric distribution. Ecol Res 20: 503-507

Norberg RA (1977) An ecological theory on foraging time and energetics and choice of optimal food-searching method. J Anim Ecol 46:511-529

Pienkowski MW (1983) Changes in the foraging pattern of plovers in relation to environmental factors. Anim Behav 31:244-264

Piersma T (1987) Production by intertidal benthic animals and limits to their predation by shorebirds: a heuristic model. Mar Ecol Prog Ser 38:187-196

Prater AJ, Marchant JH, Vuorinen J (1977) Guide to the identification and ageing of holarctic waders. British Trust for Ornithology, Tring

R Development Core Team (2005) R: a language and environment for statistical computing. R Foundation for Statistical Computing, Vienna, available at www.R-project.org

Rojas LM, McNeil R, Cabana T, Lachapelle P (1999) Diurnal and nocturnal visual capabilities in shorebirds as a function of their feeding strategies. Brain Behav Evol 53:29-43

Sassa S, Watabe Y (2007) Role of suction dynamics in evolution of intertidal sandy flats: field evidence, experiments, and theoretical model. J Geophys Res 112:F01003

Sassa S, Watabe Y (2008) Threshold, optimum and critical geoenvironmental conditions for burrowing activity of sand bubbler crab, Scopimera globosa. Mar Ecol Prog Ser 354:191-199

Stephens DW, Krebs JR (1986) Foraging theory. Princeton University Press, Princeton, NJ

van Gils JA, Spaans B, Dekinga A, Piersma T (2006) Foraging in a tidally structured environment by red knot (Calidris canutus): ideal, but not free. Ecology 87:1189-1202

Warnock N, Page GW, Ruhlen TD, Nur N, Takekawa JY, Hanson JT (2002) Management and conservation of San Francisco Bay salt ponds: effects of pond salinity, area, tide, and season on pacific flyway waterbirds. Waterbirds 25:79-92

Wetlands International (2006) Waterbird population estimates, 4th edn. Wetlands International, Wageningen

Ydenberg R, Hurd P (1998) Simple models of feeding with time and energy constraints. Behav Ecol 9:49-53

Zwarts L, Esselink P (1989) Versatility of male curlews Numenius arquata preying upon Nereis diversicolor: deploying contrasting capture modes dependent on prey availability. Mar Ecol Prog Ser 56:255-269

Submitted: June 14, 2009; Accepted: January 27, 2010 Proofs received from author(s): April 27, 2010 